Please do not remove this page

RMIT

UNIVERSITY

\title{
Looking and learning: using participatory video to improve health and safety in the construction industry
}

Lingard, Helen; Pink, Sarah; Harley, James; Edirisinghe, Ruwini

https://researchrepository.rmit.edu.au/esploro/outputs/9921862796501341/filesAndLinks?institution=61RMIT_INST\&index=null

Lingard, H., Pink, S., Harley, J., \& Edirisinghe, R. (2015). Looking and learning: using participatory video to improve health and safety in the construction industry. Construction Management and Economics, 33(9), 740-751. https://doi.org/10.1080/01446193.2015.1102301

Document Version: Accepted Manuscript

Published Version: https://doi.org/10.1080/01446193.2015.1102301

Repository homepage: https://researchrepository.rmit.edu.au

(C) 2015 Taylor \& Francis

Downloaded On 2023/04/27 00:18:47 +1000

Please do not remove this page 
Thank you for downloading this document from the RMIT Research Repository.

The RMIT Research Repository is an open access database showcasing the research outputs of RMIT University researchers.

RMIT Research Repository: http://researchbank.rmit.edu.au/

\section{Citation:}

Lingard, H, Pink, S, Harley, J and Edirisinghe, R 2015, 'Looking and learning: using participatory video to improve health and safety in the construction industry', Construction Management and Economics, vol. 33, no. 9, pp. 740-751.

See this record in the RMIT Research Repository at:

https://researchbank.rmit.edu.au/view/rmit:33855

Version: Accepted Manuscript

Copyright Statement:

(C) 2015 Taylor \& Francis

Link to Published Version:

https://dx.doi.org/10.1080/01446193.2015.1102301 


\title{
Looking and learning: Using participatory video to improve health and safety in the construction industry
}

\author{
HELEN LINGARD ${ }^{1} *$, SARAH PINK ${ }^{2}$, JAMES HARLEY $^{1}$ and RUWINI EDIRISINGHE ${ }^{1}$ \\ ${ }^{1}$ School of Property, Construction and Project Management, RMIT University, Melbourne, \\ Australia \\ ${ }^{2}$ School of Media and Communication, RMIT University, Melbourne, Australia
}

\begin{abstract}
Construction health and safety (H\&S) is usually managed using a top down approach of regulating workers' behaviour through the implementation and enforcement of prescriptive rules and procedures. This management approach privileges technical knowledge over knowledge based on workers' tacit and informal ways of knowing about H\&S. The research aimed to investigate the potential for participatory video to: (i) identify areas in which formal policies and procedures do not reflect H\&S as practised by workers; (ii) encourage creative thinking and elicit workers' ideas for H\&S improvements; and (iii) provide an effective mechanism for capturing and sharing tacit H\&S knowledge in construction organizations. Interviews were conducted in two case study organizations (CSOs) in the Australian construction industry. The results suggest reflexive participatory video enabled workers to view their work practices from a different perspective. Workers identified new hazards and reflected about the practical difficulties in performing work in accordance with documented procedures. Workers were able to re-frame their work practices and develop new, safer ways of working. Workers described how the participatory video capturing the way they work enabled them to have more meaningful input into $H \& S$ decision-making than they had previously not experienced. Workers also expressed a strong preference for receiving H\&S information in a visual format and commented that video was better suited to communicating H\&S 'know how' than written documents.
\end{abstract}

Keywords: Health and safety, participatory management, visualization, training, Australia

\section{Introduction}

The growing proceduralisation of health and safety

Bieder and Bourrier (2013) express concerns about the over-proceduralisation of workplace health and safety $(H \& S)$ in organizational management systems, suggesting that critical information that is needed by workers is buried inside long and overly complicated documents. Although $\mathrm{H} \& \mathrm{~S}$ policies and procedures are important in any organizational context, Bourrier and Bieder (2013) argue that it is inherently dangerous to rely exclusively on a rule-based bureaucratic approach to $\mathrm{H} \& \mathrm{~S}$. This is because, no matter how complex, rules and procedures cannot cover all eventualities and workers, by necessity must adapt them in the field. In reality $H \& S$ arises as a result of an ongoing interaction between formal rules and informal adaptive behaviours (Fucks and Dien, 2013).

Thus it is unsurprising that there is sometimes a gap between the prescriptions contained in formal $H \& S$ documents and the way work is carried out in practice. Borys (2012) describes $\mathrm{H} \& \mathrm{~S}$ procedures as recording work as imagined by managers and $\mathrm{H} \& \mathrm{~S}$ specialists, rather than work as performed by workers. He suggests that there can often be differences between the two. This can be a problem because if procedures do not adequately reflect the reality of task demands, they may be ignored.

Fucks and Dien (2013) warn that the over-bureaucratisation of H\&S can result in the reduction of people to mere "robots" (p.32) for whom an unthinking compliance with rules takes precedence over working safely. It is argued that over-reliance on compliance with $H \& S$ procedures can have the negative effect of diminishing people's capacity to understand and analyse situational risks. Writers on organizational resilience emphasise the importance 
of people constantly questioning safety procedures or practices that are not effective and taking the initiative to improve $H \& S$ when necessary. For example, Reason (2000) argues that organizations need to foster and maintain an abiding concern with failure and concern that their H\&S systems are fallible. Hollnagel (2010) argues that, because actual situations can differ in many ways from expected situations, it is insufficient and dangerous to rely on policies and procedures that assume predictability and stability. This may be especially true in dynamic and non-routine work, such as construction.

\section{An emphasis on the enforcement of $H \& S$}

Hale and Borys (2013) identify two different approaches to achieving workplace H\&S. Traditionally, H\&S has been managed using a "top down" approach. Such an approach emphasise enforcing workers' compliance with H\&S rules established by managers and technical specialists. These rules are seen as static, comprehensive limits to workers' freedom of choice and rule violations are seen as negative behaviour to be suppressed. When workers make errors these are attributed to individual behavioural issues, for example, laziness, complacency, a tendency to take risks or cut corners (Hayes and Hopkins, 2014). The assumption underpinning this approach is that H\&S can be maintained as long as workers' behaviour can be regulated.

However, an alternative approach to H\&S considers rules to be dynamic, and locally situated. In this alternative view workers are seen as experts whose competence enables them to adapt H\&S rules to suit their particular situation (Hale \& Borys, 2013). Human errors can and do still occur, but explanations for error are sought in the broader organizational work environment, in an attempt to reduce their chance of re-occurrence.

Research shows that the way in which H\&S is spoken and written about on construction sites very much reflects a culture of top down enforcement of management-imposed rules and procedures (Sherratt et al., 2013). Dekker (2007) argues that a procedure-driven enforcement approach to H\&S can encourage the development of a culture in which workers are blamed responsible for organizational failures and stigmatised if they are involved in workplace accidents (Dekker, 2007).

\section{Traditional H\&S training methods}

Improving H\&S capability is an important objective in the Australian Work Health and Safety Strategy 2012-2022 (Safe Work Australia, 2012) but delivery of organizational H\&S training programs in the construction industry reflects the top down management approach described above. Training typically involves an expert instructor transmitting knowledge to recipients, an approach that is arguably inappropriate and ineffective when applied to adult learning (Vella, 2002). Traditional H\&S training modes of delivery privilege technical expertise over experience, and do not reflect the fact that workers understand the H\&S hazards in the tasks they perform and have valuable knowledge about the ways in which $\mathrm{H} \& \mathrm{~S}$ risks can be controlled. Wilkins argues it is more appropriate for trainers to help construction workers learn about H\&S through facilitation and drawing on their experience, rather than by dictation (Wilkins, 2011). Indeed, research shows that a participatory (workerled) approach to developing H\&S capability produces demonstrably better results in terms of knowledge acquisition and injury prevention than traditional H\&S methods (Burke et al. 2006).

The effectiveness of traditional training approaches is also impacted by language and literacy issues. Australian construction workers have relatively low levels of educational attainment and literacy compared to workers in other sectors (ABS, 2013) and an increasing number of 
migrant workers creates additional challenges for the communication and comprehension of H\&S information (Loosemore and Trajkovksi 2006; Loosemore \& Andonakis, 2007). Thus in the construction context visual modes of information delivery may be more readily understood than text-based training materials.

\section{Aim}

In this research we aimed to explore the potential for participatory video to address some of the problems inherent in the proceduralisation of $H \& S$, current methods for managing $H \& S$, and developing workers H\&S capability. Specifically, the research sought to answer the following questions:

- Can participatory video help to identify gaps between work as imagined (by managers) and work as performed (by workers)?

- Can participatory video encourage creative thinking and elicit workers' ideas for H\&S improvements? and

- Can participatory video provide an effective way to capture and share H\&S knowledge in the construction industry?

The structure of the remainder of this paper is briefly described. First, the growing use of video to research, analyse and understand complex social and organizational issues is discussed. Secondly, the relevance of video to the management of construction H\&S is considered. The research approach and methods are then described and .qualitative data collected within two case study organisations is presented. Finally, these research results are discussed and conclusions are drawn about the potential for participatory video to be used to improve $H \& S$ in the construction industry.

\section{Video and a research and learning tool}

Forsyth (2009) observes how, with dramatic advances in affordable video and mobile technologies, people have become increasingly comfortable being filmed while performing their everyday activities. Coupled with this, social media has also enabled video to be quickly, easily and cheaply made available to a very large audience. Video is increasingly used as a tool by researchers and educators (Bottorff, 1994). For example, video has been used to stimulate self-reflection in professional training programs and other educational settings (Lee \& Wu, 2006; Moreno \& Valdez, 2007; Harford et al. 2010). Leap et al. (2009) show how video recording the delivery of a women's health service stimulated interaction between professional groups and improved trainees' learning outcomes compared to using text-based training resources. Research indicates that video generates higher levels of selfreflection (Cheng \& Chau, 2009) and peer-to-peer learning (Chan \& Leitjen, 2012) compared to traditional modes of communication and feedback delivery. Leijen et al. (2009) also note how reflexive viewing of video enables dance students to view their performance practice from the perspective of an observer, enabling them to be more self-aware and critical. Chan (2013) recently used video to facilitate and evaluate learning in construction trade skills training and Palmer (2007) used a video-based case study to deliver a professional ethics training module to engineering students. However, apart from these studies video has not been widely used to understand or improve learning outcomes in the construction industry.

Video-recording is also increasingly used to analyse and understand complex environments and behaviours (van Nieuw-Amerongen et al., 2011). In particular, the use of video to analyse work practices in high risk organizational settings is gaining popularity (Xiao \& MacKenzie, 2004). For example, Mackenzie et al. (2004) describe how video was used to analyse task performance in medical emergency situations. In particular, the video revealed 
the omission of important steps in the procedure of patient airway management. The video showed how aspects of the physical environment and pressure exerted by other team members contributed to these omissions. Reiman et al. (2014) also describe how video of truck drivers performing routine delivery tasks was analysed by workers and ergonomists to stimulate discussion about work-related risks and possibilities for improvement.

Reflexive video has been used extensively in health research to provide insight into complex socio-organizational interactions. For example, Iedema et al. (2006a) describe how, when viewing video footage of "corridor" conversations in a spinal pressure area clinic, clinicians noticed numerous infection hazards associated with the physical work environment, as well as taken-for-granted work practices. Building on this use of reflexive video, Iedema et al (2009) engaged clinicians to view and reflect on video of the everyday communication practices that occur when doctors and nurses "handover" between shifts. This resulted in a significant redesign of handover practices in a hospital to reduce risks to patient safety associated with poor communication (see also work by Carroll, 2009). Playing back video footage of in-situ professional or work practices is a particularly powerful way of bringing habitual or taken-for-granted practices to the fore, opening them up to critical review and questioning. Carroll et al. (2008) describe how, in a hospital "the visual medium [of video] enables clinicians to recognize the distributed, unspoken and risk-prone dimensions of their taken-as-given sayings, knowings and doings" (p. 381). Reflexive video has also been used to reveal and address aspects of inequality in organizational decision-making. For example, Forsyth (2009) describes how reflexive video led hospital-based scientists to actively pursue a more prominent role in decision-making relative to doctors, who traditionally have been viewed as being of higher status in the organizational hierarchy.

Perry and Talley (2001) note how reflexive video learning methods enables learners to better understand the gaps between theory and practice. Similarly, Shaw (2012) describes how reflection-on-practice involves people learning from their in-situ experiences by identifying how the reality of what happens differs from what is supposed to happen. In many cases they do not even recognise that there is a discrepancy between what they think they do and what they actually do (see also the discussion of espoused theory and theory-in-use by Argyris \& Schon, 1974). Previous research suggests that, if used reflexively, video may be helpful in understanding and exposing the previously noted gaps between work as imagined and work as performed in the construction industry.

\section{Participatory video}

Participatory video describes a set of techniques involving a group or community in creating their own film (Lunch \& Lunch, 2006, p.10). Unlike documentaries, in which subjects rarely have a say in shaping the content, participatory video enables people to "shape issues according to their own sense of what is important" and decide how they want to be portrayed (Lunch \& Lunch, 2006, p.10). This approach has often been used to provide insight into and share the experiences and daily realities of marginalised or disadvantaged groups of people. For example, Foster (2009) used participatory video to explore the experience of parenting in situations of economic disadvantage. Buchanan and Murray (2012) describe how participatory video enabled users of mental health services to express and communicate the realities of suffering from mental health disorders to others. Participatory video is particularly useful in providing a voice to people who may not otherwise be able to articulate their position or participate substantively in discourse about a particular issue. 
In Australia research shows that, despite the existence of a statutory requirement to consult workers about aspects of work that could impact their H\&S, most construction organizations do not involve workers in making strategic decisions about H\&S (Ayers et al. 2013). Participatory video is one potential mechanism for engaging workers in the design of workplaces or systems of work that have the potential to impact their health or safety. Because participatory video is widely believed to enable and empower communities or groups to pursue social change from the bottom up (see White, 2003; Shaw, 2007) it could potentially address some of the inherent limitations of the predominantly top down approach to H\&S management adopted in the construction sector.

\section{Visual pedagogy}

There is evidence to suggest that some people have a preference for visual rather than verbal learning (Mayer \& Massa, 2003). Some writers argue that to focus solely on language, literacy and speech as modes for enabling knowledge production and reproduction disregards the fact that visual ways of knowing are also important (Goldfarb, 2002). Goldfarb (2002) challenges the notion that the visual constitutes a lower form of knowledge than written or spoken knowledge. He describes how advances in computing and media technologies have dramatically changed the way people learn and increased the prominence, deployment and impact of visual learning, in schools and also workplaces.

The visual logic of construction H\&S has not been well addressed by the research community. Some researchers have used image-based tools to communicate H\&S information or understand how people think about H\&S. For example, Bust et al. (2008) trialled the use of images to communicate H\&S to migrant workers, while Zhang et al. (2014) used photographic images to elicit perceptions of $H \& S$ risk inherent in building designs and technologies. These studies are limited to the extent that moving images were not deployed and thus, they did not capture the dynamic aspect of construction work processes. To the authors' knowledge, video has not been widely used to understand and reflect on safe and healthy practice in construction. When video is used, it is to communicate a one-way topdown flow of knowledge from people assumed to possess technical expertise (i.e. a H\&S specialist) to people assumed to have little expertise (i.e. workers).

There are calls for greater use of participatory video in helping people to develop a deep understanding of themselves and their behaviour (see Azzarito \& Kirk, 2013). Video representation is arguably ideally suited to the depiction of knowledge relating to 'know how' rather than 'know what,' making it potentially very effective as a method to represent ways of working safely.

\section{Research methods}

\section{Case study design and data collection}

The research utilised an exploratory evaluation case study design in which we aimed to investigate the influence of a video-based intervention to capture and re-produce $H \& S$ knowledge in two case study organisations (CSOs). Evaluation case study designs are ideally suited to the assessment of interventions applied in real-life contexts (Yin, 1993).

At each of the CSOs, in-depth interviews were initially conducted with the manager directly involved in the video-based intervention. These interviews explored the manager's:

- experiences of the video-based intervention, and 
- perceptions of the impact and effectiveness of the intervention.

In CSO 2 the manager's interview was supplemented with a field-based observation of workers engaged in video development. Five workers who participated in the video development were also interviewed. All interviews were audio-recorded and transcribed before being subjected to content analysis.

\section{Results}

Case study organisation 1

CSO 1 was an alliance between a major construction company, engineering design firm and a government-owned statutory water authority. CSO 1 was responsible for improving, maintaining and expanding water storage systems and the distribution network for reliable and high-quality water. Following a review of CSO 1's injury/incident statistics, video development was implemented in relation to the following work tasks:

- use of a demolition saw,

- asbestos removal,

- dealing with chemical spills,

- working in a confined space, and

- building a mobile scaffold tower.

A project manager interviewed at CSO 1 described how initially, the objective of the videobased intervention in the alliance organization was to communicate OHS information to workers in a visual way. In this, the alliance was adopting a traditional "top-down" approach to communicating their documented $\mathrm{H} \& \mathrm{~S}$ policies and procedures.

However, the manager described how, during the implementation process it became apparent that the content of some of the formal policies/procedures that had been targeted for video production was questioned by workers acting out the video scripts that had been developed for them.

For example a video was made showing workers coating concrete sewerage channels with epoxy to prevent corrosion. This task is very dangerous because the channels contain aerated liquid. Falling into the channel would almost certainly result in death. In order to apply the epoxy to the channel beams, work is performed from a barge. When viewing the video showing entry to the barge, workers identified a problem that left them at risk of falling into the sewerage channel. The project manager explained: "even just a little thing, how they hooked themselves onto the safety line we identified there was a little gap. Like, there was virtually a 10 second gap [during which time] they weren't hooked on."

The manager describes how the danger inherent in the method of entry to the barge had never been noticed before. However, it was "only when [the workers] acted it out that they were conscious of 'hang on ... you have to actually undo [the harness] from the side and attach it to the base of the boat." While viewing the video, workers observed that there was a period of time during which they had no protection against falling into the sewage channel. As a result, a new work process was developed in which multiple connection points were used. This meant that workers were protected from falling into the channel at all times. The manager commented: "so it was only with just acting it out [that] the crews themselves identified it." 
According to the project manager, the benefits of video-recording work as it happened, and viewing this video reflexively with workers were soon recognised and built into the video production process.

The project manager described how in subsequent videos made at the alliance: "[The] crews themselves were the film crew and we had them act out their safe work method statement, actually role play that out and train them and supervise [them] how to use the cameras." The manager continued: "The benefit is [in] getting the guys' input... making them act it out rather than sitting in a crib shed half asleep in the morning...that's a much more powerful engagement mechanism."

The same manager described how workers were initially sceptical but "pretty soon the guys started coming to us with ideas about more stuff we could do." He reflects that: "One of the benefits we saw was it [the participatory video process] allowed us to build great engagement with the workforce.....it just created that openness that 'Look, we're here to listen to what you want to say and we're willing to put in place your ideas into our systems' and that's what makes safety more credible really."

In CSO 1, the project manager also observed how "during the [participatory video] process it's amazing how many things the crews themselves picked up... they said 'oh actually what we do in practice is not what the document says. Actually we do this.' So it actually I think resulted in improvements to written safe work method statements to better reflect what crews were doing."

For example, while members of a scaffolding erection crew were viewing video depicting the standard erection procedure for a mobile tower scaffold. While watching and reviewing the footage, the workers identified a period of time during which work was performed adjacent to an unprotected live edge. The manager observed: "There was just one phase, for 30 seconds, where they were unprotected...so we went back out to the worksite with the crew [and] the supplier and said 'how do you reckon we fix it?"' The crew spent several hours trying different erection sequences and eventually worked out a new method for erecting the scaffold tower, using temporary platforms and horizontal bracing. This eliminated the requirement to work adjacent to an unprotected edge at any stage in the erection sequence. The manager commented: "the previous way of building [the scaffold] had been custom and practice for decades...no one had sort of thought twice about it but once you saw it on the screen it didn't look quite right... and we just got the guys who had been doing it for years to try and find a way to fix it and in the end they did."

Case study organisation 2

CSO 2 supplies and installs insulation and energy efficiency products in the residential and commercial building sectors of the Australian construction industry. CSO 2's top risk areas, i.e. those with the potential to cause a workplace fatality are:

- $\quad$ electrical safety,

- working at heights,

- traffic management,

- mobile plant, and

- $\quad$ working in hot conditions.

In CSO 2 workers were engaged in a participatory process to develop videos about electrical isolation, load restraint procedures, trailer hitching, working in hot conditions and accessing 
ceiling spaces. The H\&S Manager at CSO 2 described how, although initially hesitant, workers soon became involved in the video development. She comments "...so yeah, it was that whole engagement. If you're getting them [the workers] to do it, if you make it a bit of fun, don't make it too serious, and they muck around a bit because they all don't like the initial thought of doing a video, it doesn't enthral them, but then they got into it and saw the benefits."

The manager described how workers in the insulation trades generally "don't like to read and write" but "for some reason they don't mind handling a script [because] they understand, they've seen the filming done onsite, they've seen how it all works."

The manager also noted how the videos provide workers with practical and useable H\&S information, i.e. "the stuff they need out onsite. You're not talking about the Regs and the Acts, it's not about that. It's about just what you really need to know while you're out there on the site." She described workers' antipathy to written H\&S procedures and contrasts this to the worker-developed video, observing: "They [the workers] can see that it's not fixed in concrete. They have an ability to improve it and contribute to it and it's made up of what comes from them."

According to the manager at CSO 2, the participatory video process has increased workers' willingness to share H\&S information and ideas. She observed that, since the organisation engaged its workforce in creating $H \& S$ videos, workers have interacted more openly with H\&S staff in the corporate office. The manager commented: "[Previously] there was no way you could get the operations guys to come in the office because they thought they were going to be, yeah, performance managed... and now they're coming in quite freely and making a point of dropping by in here, so it's good." She also describes how CSO 2 "had 100\% [of workers and contractors] turn up for the end of year barbeque and they all wanted to see the... video, and that's never happened before."

The manager has also observed an increased level of trust between workers and management. She commented: "The camaraderie is great, which opens up free thinking and free speech and things come forward. When you ask their [the workers'] opinion, they feel valued."

In CSO2, the video production process has also identified opportunities to improve the way work is undertaken. For example, during the scripting and development of a video about working safely in the heat, workers observed that eating hydrating foods is important to restore energy and fluid in the heat. As the manager observed: "Everyone talks about hydration but no-one talks about hydrating food and when you lose your appetite and don't eat it can add to your fatigue." The workers suggested the slogan "rehydrate and refuel" and the video they produced included a sequence showing a worker taking a rest break, opening a small portable insulated food container and eating fresh pineapple. Advice relating to the consumption of hydrating food is now also included in the company's written H\&S manual.

The manager at CSO 2 also commented that workers' ability to retain and recall H\&S information has increased. In particular, she described how the State Manager of her business telephoned a number of sub-contracted workers to ask them whether they remembered the content of the company's electrical isolation procedure. Having had access to the video relating to this, the contractors replied "you've got to be kidding, who doesn't know that?" 
The videos have also helped workers engaged by CSO 2 to communicate important H\&S information upwards in the supply chain. As the organization is engaged to install insulation, the worksites at which they operate are not under their control, but are controlled by principal contractors or builders. The H\&S Manager describes how the situation in relation to electrical safety was "untenable" because "A situation had developed out on site where it had become a gentleman's agreement between the trades and ourselves 'okay you need power so we won't isolate because of the inconvenience that it would cause out on job sites'. Rather than challenge the status quo, that situation had become expected."

However, the video that was created by the workers showing the procedure for electrical isolation prior to installing insulation "empowered the guys to understand the risks and be able to communicate them and also have that position brought to builders [their clients] in a way that they can see it and understand it immediately."

At CSO 2, the video development process also revealed a significant gap between work as imagined and work as practised. Much of the installation work undertaken by the company involves accessing ceiling manholes at a height of between 2.4 and 2.7 metres from the floor. The company has a safe operating procedure for the safe use of ladders and working at height. It was decided that this would be the subject of a participatory OHS video. The script was developed based on the documented safe operating procedure and distributed for comment. The H\&S Manager commented that "no-one had an issue with it theoretically." However, when it came to the filming, the H\&S Manager described how "shooting it and viewing it through the camera's eye, we had to stop... the camera doesn't lie." She explained: "To place a straight ladder at the 1:4 ratio just doesn't work, you can't get a body in there as well because it blocks off the access and you have to contort yourself to actually get in [to the ceiling space].”

The safe operating procedure also requires the ladder extend $900 \mathrm{~mm}$ beyond the "step off" point, which is almost impossible to achieve due to conduits, cables, beams and other obstructions. The small size of the manholes does not allow adequate entry for the ladder, the worker and the pack of insulation to be installed. The H\&S Manager described the process for passing ceiling packs through the manhole. Workers used a straight ladder which meant they had to contort their bodies to manoeuvre themselves into the ceiling space, then move the ladder to get the packs in. "It's pretty cumbersome" she explained. However, if the workers used an 'A-frame' ladder, "which they do because they can't use a straight ladder," they are forced to work unsafely because they have to step off the top rung of the 'A-frame' to get their bodies up into the ceiling space.

The practical difficulties associated with the task became apparent during the filming of the video. The filming was halted and the company embarked on a project to find an industrial rated solution for accessing ceiling manholes at a height of 2.4-2.7 metres. It was a requirement that the solution should also be able to extend $900 \mathrm{~mm}$ beyond the manhole. The H\&S Manager has consulted workers and identified an alternative access system used by arborists. The access system has curved rungs which envelope the body "so it is easy to get three points of contact and you don't need the 1:4 ratio lean so you can place it so it does not encroach on the manhole opening space and there is a clear shaft opening for the ceiling packs". 
The system is currently undergoing a few engineering modifications before it is trialled. The H\&S Manager explains, "we've had to stop [the filming] while we come up with this solution, but this is looking really good."

\section{Workers at CSO 2}

Five insulation installation workers employed by CSO 2 were interviewed about their experience of the video-based intervention. These interviews were conducted on-site while workers were participating in the development of a video about electrical isolation in the commercial building sector. These workers were purposefully selected because they were participating in the video production and the intention was to gain insight into their experiences of this process. Themes emerging from the interview data are presented below. Workers were asked about:

- their preferences for receiving H\&S information, i.e. through documents, videos or formal training activities.

- the ways that they currently access knowledge about H\&S,

- whether they liked making the H\&S videos, and

- whether in the process of making the video they were learning new things about H\&S.

Perceived benefits associated with visual communication

All five workers commented that presenting $H \& S$ information visually is more effective than using text-based methods. Participants commented that workers would be more likely to look at and understand videos than written H\&S procedures. One of the workers described how verbal instructions communicate what is required but video actually shows workers how to do what is required. He commented: "It's a lot easier to show someone what we're trying to say. We could just to sit here and verbally speak about it but if you put your verbal words into a video, people are going to sit back and go "now I know what he's actually trying to say." Another worker expressed a similar view, commenting: "I just think it's a lot easier to visually show that you're not to shoot a pin into this area, as to 500 words or something to describe the same thing."

The workers generally agreed that it was easier to retain and recall the content of videos as compared to text-based H\&S resources. One remarked: "If you watch [something] that's it, that's going to be keeping in your brain. You remember more in one movie than one letter, paperwork or newspaper or whatever you read. You remember what you see."

The workers also identified the fact that construction workers generally do not like to read written material. For example one worker commented: "You get a lot of people, especially in the construction industry, a lot of people who sit there and don't take in what they see on paper. They're more 'hands on' like. The whole construction industry is. It's more 'hands on'." Another commented: "I think it [video] is the best way for people to learn. I mean, just from my point of view, being on a building site I don't read too much at all, especially when I get on site. I'm here to do a job, you know what I mean?"

The workers commented that watching a video was much less demanding than reading documentation which is often long, complex and inaccessible for people with poor literacy skills. For example, one of the workers reflected: "There's just so much information and it's just not practical to sit there for three, four hours because I'm not very good with the English language so for me to read a document like that would take me half a day and they're not going to let you sit there and do that...you're also going to embarrass yourself in a room with 20 other people... so there's pressures to sign them off." 
Workers' ways of knowing about $H \& S$

Most of the workers' commented that their primary source of H\&S knowledge was developed through observing and imitating those around them. One described how he knew about H\&S by "just sort of learning from the people that I was with." Another described how "the young learn from the old, don't they?" However the limitations inherent in reliance on informal on-the-job learning about H\&S became evident when one worker described how information about the need to maintain clearance before shooting pins into masonry adjacent to conduits was discussed during the video scripting process. He commented: "I thought it would have been something that someone would have told me in my whole learning process of being here... but it does not seem to be happening."

Another worker described how it is sometimes hard for written and verbal instructions to fully capture H\&S knowledge. He commented: "We can't put everything in there [the $H \& S$ procedure] because sometimes it's something you can't write in there because it's knowing.... You can make a note but, yeah, it's hard to describe everything in words." Workers' involvement and engagement in the video-based intervention

All of the workers appreciated being involved in making the H\&S video. When asked whether he had enjoyed himself during the script development session, one worker responded: "I certainly did, yeah. It's good to give people input, especially when you realise that it's going to improve something." Another commented: "Yeah, it's good for everyone to throw their input in and you just learn a lot more about what could be done and it gets your mind thinking."

The workers described how they felt valued because the company had taken the time to really understand (from their perspective) the way that they work and the H\&S aspects of their jobs. For example, one commented: "It was good. It was actually good, you know, getting my voice heard and actually people sitting there and actually taking it in what I was saying, rather than just going over someone's head or just turning a blind eye to it. It actually feels like something or progress can be made or people actually listened."

Several workers commented that the content of the videos was likely to be realistic and useful because of the participatory nature of video development. One commented: "Yes, I think it's the best way because if [the material] is from people working on the site, it's going to be spot on. Exactly what is happening."

\section{Opportunities to learn about $H \& S$}

Several of the workers who were interviewed commented that they had learned important new H\&S information when reviewing and discussing the content of the video. For example, one worker stated: "Some things I didn't actually fully take into consideration before, got brought to my attention...so it was actually good...there was actually some points there I'm glad that got brought up and that would not normally be brought up."

Workers described how sharing information from different perspectives in the video development process presented an important learning opportunity. One commented: "It's good having different points of view from people that have, you know, got different outlooks on different things...Like with guys [like us] we work on the site - and then getting like another vision from someone that's just come into it and you go 'okay, actually what about this then?' And you sit back and go 'oh actually we didn't take that into consideration.',"

Several of the workers described how they were previously unfamiliar with some of the important H\&S information written into the video. One commented: "I learned that you're 
not to shoot a pin less than $300 \mathrm{~mm}$ from a live wire. Never knew that at all... and that's a big one. I also learned that conduit sometimes is running through the concrete slab. I didn't know that."

\section{Discussion}

Creating a different view of work

Pink et al. (2014) note how institutional and informal knowledge intermingle in the way that workers practice H\&S. Iedema et al. (2009) describe how video of day-to-day work practices helped medical practitioners to re-apprehend and reframe their work processes, and provided the opportunity to redesign these processes in their everyday practices. According to Iedema et al. (2009) visual moving images place people in a space of transformation because viewing one's work on a screen generates a higher level meta discourse about the way work is performed. Video captures the audio and visual aspects of work as it is undertaken in situ and provides people with a different view of their work. Our research shows how video created the opportunity to reframe $H \& S$ within a broader understanding of how work is done. This is illustrated by the case examples presented in this paper. The mobile scaffold and barge entry examples reveal how hazardous aspects of work, that were enacted by workers on a daily basis, were identified as being unacceptable only after they were viewed on screen. Iedema et al. (2009) describe how video enables people to view their work "from under a different aspect" (p.299). In our examples this ability did more than facilitate conversation about the work tasks that were shown, it also prompted viewers (both workers and managers) to consider larger questions relating to acceptability of $H \& S$ risk. The video was also a catalyst for creativity and the development of safer, more effective ways of working.

The example of the ladder access to ceiling spaces also illustrates how video can reveal the difference between espoused theory and practice. The content of the taken-for-granted safe operating procedure for entry into a ceiling space had been accepted as being correct "in theory." However, filming revealed the impossibility of working in accordance with this procedure. A substantial gap between knowledge about what should be done (as documented in the safe operating procedure) and workers' knowledge about how to perform the task was readily apparent. Once understood, this gap could be addressed and a safer, practical and effective way of accessing ceiling spaces was found.

Stimulating creative thinking and workers' ideas

A key feature of participatory video is that it "firmly locates expertise about practice (and possibilities for its redesign) with participants" (Forsyth et al., 2009, p.215). The research reveals how H\&S improvements can be realised when workers are engaged, through participatory video, in critiquing their own work practices and designing better ways of working.

The benefits associated with engaging workers in the reflexive viewing of video footage were immediately apparent in the problems identified and H\&S improvements that were achieved in developing a safer way of erecting the mobile tower scaffold and entering the barge to coat the sewerage channel. However, past research reveals that actively seeking employee participation and feedback in H\&S planning, decision-making and improvement results in high standards of H\&S performance (HSE, 2005, Torner \& Poussette, 2009; Lingard et al. 2014). The interviews conducted at CSO 1 and CSO 2 both indicated that, in addition to making practical improvements to featured work tasks, broader environmental and cultural benefits were also realised. These included improved two-way communication about H\&S, 
increased worker involvement in H\&S activities and elevated levels of trust between workers and managers. For example, the manager interviewed at CSO 1 explained how the system dramatically improved $\mathrm{H} \& \mathrm{~S}$ communication in his organization, commenting: It [the videobased system] just created that openness that 'Look, we're here to listen to what you want to say and we're willing to put in place your ideas into our systems' and that's what makes safety more credible really."

\section{Accessing and re-producing workers' tacit knowledge}

The traditional top-down approach to $H \& S$ management has privileged technical expertise over workers knowledge about how to work safely. However, as Pink et al. (2014) note, workers engage tacit and informal ways of knowing when they practice H\&S. Tacit knowledge is difficult to transfer to another person by means of writing it down or verbalizing it (Polanyi, 1958). This type of knowledge can be described as 'know how,' rather than 'know what.' For example, knowing how to use a complex piece of equipment or perform a complicated work task safely are forms of tacit knowledge. In many cases the people who possess tacit knowledge may not be aware of their knowledge or understand how valuable it could be to others. Construction workers are also unlikely to possess the skills to easily communicate knowledge to others. Workers at CSO 2 described how hard it is to describe aspects of their work "in words" and indicated that they felt it was a lot easier and more effective to show people how to work in a video.

The worker interviews at CSO 2 also revealed that traditional ways of knowing about $\mathrm{H} \& \mathrm{~S}$ were largely based on observation and on-the-job learning. However, these methods produced gaps and inconsistencies. For example, the participants expressed some surprise that they had never been made aware of the requirement for minimum clearance when installing fixings adjacent to conduits. These workers also commented that the participatory video process had permitted different workers' perspectives and knowledge to be captured, shared and critiqued. As far as they were concerned, the resulting video would be a more complete and realistic representation of how to work safely because the content was developed in a collaborative manner and subjected to workers' peer review.

The interview data also suggests that video may be a more effective way of sharing and communicating H\&S information among construction workers, than alternative text-based methods. Workers expressed a general antipathy towards reading and the preference for visual communication was also noted by managers. For example, the project manager at CSO 1 commented: "The guys are often in a trade because the written word is not their specialty and it's more seeing and doing, it's more visual. I think in the industry we have to become more visual in communication."

\section{Conclusions}

Previous use of video in $H \& S$ has been limited to using video to communicating the $H \& S$ knowledge of technical specialists to workers in the form of instructional H\&S videos. This approach privileges technical expertise over experience. It is also underpinned by the assumption that H\&S can be maintained as long as workers' behaviour can be regulated. In this research we evaluated an alternative use of video in relation to H\&S. Participatory video reverses the logic of traditional H\&S thinking, locating expertise about good practice with participants. Data were collected in two CSOs that had implemented a participatory video approach. The results revealed how workers' critical and reflexive analysis of video footage revealed H\&S problems inherent in taken-for-granted work tasks. The video also revealed 
inconsistencies between work as imagined and work as performed, and, in one instance, highlighted the practical impossibility of working in accordance with standard documented work procedures. The new insights generated by viewing video footage from the perspective of an outsider allowed ways of working to be re-framed and re-apprehended, with the result that high risk work tasks were re-designed to improve H\&S. Workers and managers at both CSOs described high levels of worker engagement, open communication and trust arising as a result of the participatory video process. Workers also expressed a strong preference for visual ways to know about H\&S. They explained that most of their current H\&S knowledge had been gained through observing others rather than reading H\&S documents. The workers also described how H\&S information representing "know how" is sometimes difficult to verbalise but can be much more easily demonstrated.

\section{Limitations and further research}

Once completed, the worker-created videos created in the participatory video process are made available to other workers at the respective CSOs' work sites using quick response code technology. Workers are able to access these videos using their mobile phones or other digital devices. Research is ongoing to investigate the ways in which construction workers use mobile/digital technology to interact with and use this video content.

The research presented in this paper was inherently limited in investigating the use of participatory video at two CSOs in Australia. The ability to generalise the findings to other construction organisations is limited. However, the results provide some preliminary evidence that participatory video has the potential to address some key challenges associated with management of $H \& S$ in the construction industry, notably an over reliance on written procedures, ineffective training approaches and a heavy emphasis on enforcement of rules rather than engagement of workers.

\section{Acknowledgement}

This project received funding from the Victorian Department of Business and Innovation, through its Business Research and Development Voucher program, and was supported by CodeSafe Solutions.

\section{References}

Argyris, C., \& Schön, D. (1974). Theory in practice: Increasing professional effectiveness. San Francisco: Jossey-Bass.

Azzarito, L. and D. Kirk, (2013), Pedagogies, Physical Culture and Visual Methods. Oxford: Routledge Australian Bureau of Statistics. (2013). 4228.0 - Programme for the International Assessment of Adult Competencies, Australia, 2011-12, Canberra.

Ayers, G., Culvenor, J., Sillitoe, J. \& Else, D., (2013), Meaningful and effective consultation and the construction industry of Victoria, Construction Management and Economics, 31 (6), 542-567

Bieder, C. \& Bourrier, M., (2013), Trapping safety into rules: How desirable or avoidable is proceduralization? Ashgate, Farnham.

Bottorff, J. L., (1994), Using videotaped recordings in qualitative research, in Morse J. M. (Ed), Critical Issues in Qualitative Research Methods, Sage, Thousand Oaks, 244-261.

Borys, D., (2012), The role of safe work method statements in the Australian construction industry, Safety Science, 50, 210-220.

Buchanan, A. \& Murray, M., (2012), Using participatory video to challenge the stigma of mental illness: a case study, International Journal of Mental Health Promotion, 14 (1), 35-43,

Burke, M. J., Sarpy, S. A., Smith-Crowe, K., Chan-Serafin, S., Salvador, R. O. \& Islam G. (2006), Relative Effectiveness of Worker Safety and Health Training Methods, American Journal of Public Health, 96, (2), 315-324

Bust, P. D., Gibb, A.G. F. \& Pink, S. (2008). Managing construction health and safety: Migrant workers and communicating safety messages. Safety Science. 46, 585-602.

Carroll, K., Iedema, R. \& Kerridge, R, (2008), Reshaping ICU Ward Round Practices Using Video-Reflexive Ethnography, Qualitative Health Research, 18(3) 380-390. 
Carroll, K., (2009), Outsider, insider, alongsider: Examining reflexivity in hospital based video research, International Journal of Multiple Research Approaches (2009) 3: 246-263.

Chan, S., (2013), Using videos and multimodal discourse analysis to study how students learn a trade, International Journal of Training Research, 11(1), 69-78.

Chan, S. \& Leitjen, F., (2012), Using feedback strategies to improve peer-learning in welding, International Journal of Training Research, 10 (1), 23-29.

Cheng, G. \& Chau, J., (2009), Diital video for fostering self-reflection in an e-Portfolio environment, Learning, Media and Technology, 34 (1) 337-350.

Dekker, S. 2007. Just Culture: Balancing Safety and Accountability, Aldershot, Ashgate.

Forsyth, R., Carroll, K. \& Reitano, P. (2009), Illuminating everyday realities: The significance of video methods for social science and health research, International Journal of Multiple Research Approaches, 3, 214-217.

Forsyth, R., (2009), Distance versus dialogue: modes of engagement of two professional groups participating in a hospital-based video ethnographic study, International Journal of Multiple Research Approaches, 3(3), 276289.

Fucks, I. \& Dien, Y. 2013. 'No Rule, No Use'? The Effects of Over-Proceduralization. In: Bieder, C. \& Bourrier, M. (eds.) Trapping Safety into Rules: How Desirable or Avoidable is Proceduralization? Farnham: Ashgate.

Goldfarb, B. (2002), Visual Pedagogy: Media Cultures of Education in and Beyond the Classroom. Durham, NC: Duke University.

Hale, A. \& Borys, D.(2013) Working to rule or working safely? Part 2: The management of safety rules and procedures. Safety Science. 55, pp. 222-231.

Hayes, J. \& Hopkins, A. 2014. Nightmare pipeline failures: Fantasy planning, black swans and integrity management, Sydney, $\mathrm{CCH}$

Harford, J., MacRuairc, G. \& McCartan, D., (2010), 'Lights, camera, reflection': using peer video to promote reflective dialogue among student teachers, Teacher Development, 14, (1), 57-68

Hollnagel, E., (2010), Extending the scope of the human factor, In In E. Hollnagel (Eds.), Safer complex industrial environments, CRC Press, Boca Raton, 37-59.

Iedema, R. , Merrick, E. T., Rajbhandari, D., Gardo, A., Stirling, A. \& Herkes, R., (2009), Viewing the takenfor-granted from under a different aspect: a video-based method in pursuit of patient safety, International Journal of Multiple Research Methods, 3 (3) 290-301.

Iedema, R., Long, D., Forsyth, R. \& Lee, B. B., (2006a), Visibilising clinical work: Video ethnography in the contemporary hospital, Health Sociology Review, 15 (2) 156-168.

Iedema, R., Forsyth, R., Georgiou, A., Braithwaite, J., \& Westbrook,J., (2006b),Video research in health, Qualitative Research Journal, Vol. 6 (2), 15 - 30

Kamara, J. M., Augenbroe, G., Anumba, C. J. \& Carrillo, P. M. (2002), Knowledge management in the architecture, engineering and construction industry, Construction Innovation 2002; 2: 53-67.

Leap, N., Sandall, J., Grant, J. Bastos, M. H. \& Armstrong, P., (2009), Using video in the development and field testing of a learning package for maternity staff: Supporting women for normal childbirth, International Journal of Multiple Research Methods, 3 (3) 302-320

Lee, G. C., \& Wu, C. (2006). Enhancing the teaching experience of pre-service teachers through the use of video in web-based computer-mediated communication (CMC). Innovations in Education and Teaching International, 43, 369-380.

Leijen, A., Lam, I., Wildschut, L., Simons, P. R. J. \& Admiraal, W. (2009), Streaming video to enhance students' reflection in dance education, Computers and Education, 52 (1), 169-176.

Lingard, H., Zhang, R., Blismas, N., Harley, J. \& Wakefield, R., (2014), Health and Safety Culture, Australian Constructors Association.

Loosemore, M. \& Andonakis, N. (2007) Barriers to implementing H\&S reforms - The experiences of small subcontractors in the Australian Construction Industry. International Journal of Project Management 25 (2007) 579-588

Loosemore, M. \& Lee, P. (2002) Communication problems with ethnic minorities in the construction industry. International Journal of Project Management. Volume 20, Issue 7, Pages 517-524

Lunch, N. \& Lunch, C., (2006), Insights into participatory video: A handbook for the field, Insightshare, http://insightshare.org/resources/pv-handbook.

Mackenzie, C. F., Xiao, Y., \& Horst, R. (2004). Video task analysis in high performance teams. Cognition, Technology \& Work, 6(3), 139-147.

Mayer, R. E. \& Massa, L.J.., (2003), Three Facets of Visual and Verbal Learners: Cognitive Ability, Cognitive Style, and Learning Preference, Journal of Educational Psychology, 95, (4), 833-846

Moreno, R., \& Valdez, A. (2007). Immediate and delayed effects of using a classroom case exemplar in teacher education: The role of presentation form. Journal of Educational Psychology, 99, 194-206.

Pink, S., Morgan, J. \& Dainty, A. (2014). Safety in movement: Mobile workers, mobile media. Mobile Media \& Communication, 2(3) 335-351 
Polanyi, M., (1958), Personal knowledge : towards a Post-Critical Philosophy. University of Chicago Press. Reason, J., (2000), Safety paradoxes and safety culture. Injury Control and Safety Promotion, 7(1), 3-14.

Reimann, A., Pekkala, J., Väyrynen, S., Putkonen, A., Forsman, M., (2014), Participatory Video-Assisted Evaluation of Truck Drivers' Work Outside Cab: Deliveries in Two Types of Transport, International Journal of Occupational Safety and Ergonomics, 20, (3), 477-489.

Safe Work Australia. (2012), Australian Work Health and Safety Strategy 2012-2022, Commonwealth Government of Australia, Canberra.

Saksvik, P. Ø. \& Quinlan, M., (2003), Regulating Systematic Occupational Health and Safety Management: Comparing the Norwegian and Australian Experience. Relations Industrielles/Industrial Relations, 58, (1) 33-59.

Shaw, J., (2012),Interrogating the gap between the ideals and practice reality of participatory video, in Milne, D., Mitchell, C. \& de Lange, N., (Eds), Handbook of Participatory Video, AltaMira Press, Lanham, Maryland, pp. 225-241

Shaw, J. (2007), Including the excluded: collaborative knowledge production through Participatory Video, in Inclusion through Media, T. Dowmunt, M. Dunford and N. von Hemert (Eds.) University of London, London.

Sherratt, F., Farrell, P. \& Noble, R., (2013), UK construction site safety: Discourses of enforcement and engagement. Construction Management and Economics, 31 (6), 623-635.

Palmer, S. (2007), An evaluation of streaming digital video resources in on and off-campus engineering management education, Computers and Education, 49 (2), 297-308.

Perry G. \& Talley S., (2001), Online video case studies and teacher education, Journal of Computing in Teacher Education, 17 (4), 26-31.

Törner, M \& Pousette, A., (2009), Safety in construction - a comprehensive description of the characteristics of high safety standards in construction work, from the combined perspective of supervisors and experienced workers. Journal of Safety Research, 40(6), 399-409.

Trajkovski, S. \& Loosemore, M., (2006), Safety implications of low-English proficiency among migrant construction site operative. International Journal of Project Management, 24,pp. 446-452.

van Nieuw-Amerongen, M. E., Kremers, S. P. J., De Vries, N. K., \& Kok, G. (2009). The use of prompts, increased accessibility, visibility, and aesthetics of the stairwell to promote stair use in a university building. Environment and Behavior.

Vella, J.K.(2002), Learning to listen, learning to teach: The power of dialogue in educating adults.

San Francisco: Jossey-Bass.

Xiao, Y., Mackenzie,C. F. (2004), Introduction to the special issue on video-based research in high risk settings, Cognition, Technology and Work, 6: 127-130.

Wilkins, J. R. (2011), Construction workers' perceptions of health and safety training programmes. Construction Management and Economics, 29, 1017-102.

White, S. A. (2003), Participatory video images that transform and empower, Sage Publications, New Delhi

Zhang, R., Lingard, H., Blismas, N., Wakefield, R., \& Kleiner, B., (2014), Analysis of difference/similarity between construction project participants' work health and safety (WHS) risk perceptions, Proceedings of the CIB W099 Conference, Achieving Sustainable Construction Health and Safety, Lund, Sweden, 468-480. 